\title{
How Do Social Structures Become Taken for Granted? Social Reproduction in Calm and Crisis
}

\author{
Ryan Gunderson $^{1}$ (D)
}

Accepted: 8 June 2021 / Published online: 6 July 2021

(c) The Author(s), under exclusive licence to Springer Nature B.V. 2021, corrected publication 2021

\begin{abstract}
This paper identifies experiential processes through which social structures become taken for granted, termed processes of "structure marginalization". Passive processes of structure marginalization relegate social structures to the margin of experience without the use of higher-order cognitive acts such as evaluation and reflection. Examples include adapting to social structures via routine and habitual practices (material reification), a lack of conscious awareness of the complexity, historical formation, and other details of social structures (ignorance), and rendering social structures irrelevant when they are unreflectively judged to be of no value for achieving ends (nullification). Active processes of structure marginalization reflectively and discursively relegate social structures to marginal consciousness. Examples include the use of naturalistic and necessitarian explanations for the social order that implicitly justify it as inalterable or "just the way things are" (discursive reification), normative justifications for the status quo (legitimation), and conscious awareness of one's powerlessness to control social-structural conditions (helplessness). Active processes of structure marginalization originate in passive processes. The goal of the typology is to explain, at the level of experience, why social structures typically remain unproblematic and unnoticed in everyday life, even during periods of social crisis and change or when existing structures produce harmful effects.
\end{abstract}

Keywords Phenomenology $\cdot$ Critical theory $\cdot$ Gurwitsch $\cdot$ Husserl $\cdot$ Relevance/ irrelevance $\cdot$ Reification $\cdot$ Passive and active constitution

Man grows used to everything, the scoundrel! Rodion Raskolnikov, Crime and Punishment (Dostoyevsky).

Ryan Gunderson

gunderrm@miamioh.edu

1 Department of Sociology and Gerontology, Miami University, 375 Upham Hall, Oxford 45056, $\mathrm{OH}$, USA 


\section{Introduction}

The question of why subjects attend to particular aspects of experience, what Schutz (1967b: 250) calls the problem of relevance and Scheler (1980: 72f.) elevates to the central question of the sociology of knowledge, has been approached from diverse angles in sociology (see Zerubavel 1997). Reflecting on why consciousness attends to certain aspects of experience simultaneously asks, though sometimes only implicitly, why it does not attend to other aspects. The focus here is on the latter realm of disattention, or, the taken-for-granted (Zerubavel 2018). The taken-for-granted is the dimension of experience that, with different shades of meaning, Schutz (1970; see Zerubavel 2015) calls "the irrelevant," Goffman (1974) calls "out-of-frame" activity, Bourdieu (1977) calls “doxa," Brekhus (1998) calls "the unmarked," and, Gurwitsch (1964), a central influence in this paper, calls "the margin". The specific goal here is to identify how social-structural forces become taken for granted, both in periods of social calm and crisis.

It may seem self-absorbed for sociologists to ask why non-sociologists do not pay more attention to the dimension of reality that sociologists happen to find interesting. However, unlike a mycologist or astronomer, for example, who could also ask why the person on the street does not often pay attention to their objects of fascination, social structures, in comparison to fungi and the universe, are continually and constantly remade and shaped by the everyday actors who constitute these forces, despite being taken for granted. Further, social structures impact the probability that one might contract various diseases, attend college, be poor or rich, be mentally healthy, and have access to affordable and healthy food, clean drinking water, affordable and safe shelter, and medical care.

Given their impact on one's life chances and well-being, it is not unreasonable to assume that people would be more attentive to the social-structural forces that shape their lives. This is especially true in periods of crisis and rapid social change, when social forces are made strange and questioned, rather than remaining familiar and taken for granted (Bourdieu 1977: 168f.; Foucault 1985: Part 1; Gunderson 2020a: $62 \mathrm{ff}$.). For example, whether one is a sociologist or not, one is almost compelled to ask fundamental questions about the structure of society following an ineffective response to a global pandemic, massive levels of wealth and income inequality, the rapid development and spread of new forms of digital technology, and the risk of catastrophic climate change. Yet, even during an age like our own, the typical person on the typical day, including the typical sociologist when not teaching or researching, spends more time attending to salary schedules, a new Netflix series, medical bills, and the fastest route to get their children to school during a traffic jam than they do reflecting on capitalism, the culture industry, models of healthcare systems, and ideological state apparatuses. How does the sociological imagination, rooted in the experiences of everyday life, shift back into a general disattention to social structure?

This paper makes two contributions to the literature. First, it seeks to conceptualize experiential processes in social context that relegate awareness of socialstructural forces to the margin of experience, i.e., that render social structures 
irrelevant, normal, unproblematic, taken-for-granted, unnoticed, and even invisible. I identify two broad levels of structure marginalization, a concept defined below. First are passive processes of structure marginalization that constitute social structures as irrelevant before there is any active reflection on the part of the subject. Second are active processes of structure marginalization, which reflectively and discursively constitute social structures as irrelevant.

The second contribution is to the question of social reproduction: Why and how do societies maintain their basic structures over time, even when they cause actors great harm (see Himmelweit 1991)? The question of social reproduction was summarized well by Wright when discussing components of theories of social emancipation, theories which assume that:

the structures and institutions that generate the forms of oppression and social harms identified in the diagnosis and critique of society do not continue to exist simply out of some law of social inertia; they require active mechanisms of social reproduction. This proposition is based on a counterfactual argument: since these structures and institutions impose real harms on people, in the absence of some such active process of social reproduction, the people harmed by the existing social arrangements would resist these harms and challenge these institutions in ways which would result in their transformation. (2010: 26)

Thus, to explain the "relative stability of oppressive structures and institutions," one must identify "interconnected mechanisms of social reproduction which block or contain such a challenge" (Wright 2010: 26). By classifying the experiential processes that render social structures irrelevant, the concept of structure marginalization provides a non-functionalist explanation for the reproduction of the current order in times of calm and crisis. The analysis focuses on social reproduction at the level of experience and is meant to supplement, not replace, macro-level theories of social reproduction.

This paper emerged from past attempts to develop analytically rigorous conceptualizations of ideology and reification to explain the persistence of, and lack of collective action to transform, social structures that cause great harm, especially those driving climate change (e.g., Gunderson et al. 2020; Stuart et al. 2020). To accomplish this goal, I have found that the phenomenological tradition, especially the ideas of Alfred Schutz and Aron Gurwitsch, offers a treasure chest of helpful concepts for deepening Marxist accounts of ideology and reification (e.g., Gunderson 2020a, b, 2021, in review1; Gunderson et al. 2020). Although there are irreconcilable differences between phenomenology and critical theory (e.g., Adorno 1982), despite their parallels (Paci 1972), my approach is akin to past Marxists who opportunistically usurped phenomenological and ethnomethodological concepts to assist in explaining the reproduction of capitalism in everyday life, while simultaneously remaining skeptical of the project of phenomenology and its offshoots on various grounds (e.g., Chua 1977; Sallach 1973). This manuscript strives to build upon and synthesize work in these overlaps with the 
help of Gurwitsch's notion of "marginal consciousness" and Husserl's distinction between "activity" and "passivity".

In what follows, I first explain what is meant by "social structure" and "structure marginalization". Following, I classify three forms of passive structure marginalization: material reification, ignorance, and nullification. Then, after a discussion of how periods of social crisis and change allow for the possibility of collective interventions to consciously change society, I conceptualize three active forms of structure marginalization that undermine this possibility: discursive reification, legitimation, and helplessness. The paper concludes with suggestions for future research to explore how the concept of structure marginalization may deepen sociological understanding of the relations between the experience and reality of social structure.

\section{Social Structure and Structure Marginalization}

To ask why social structures are typically relegated to the margin of experience, one must first define what is meant by "social structure" and "the margin of experience". This section first summarizes the notion of social structure and then begins conceptualizing the notion of structure marginalization.

\section{Social Structure}

It can be embarrassing for sociologists to explain to other sociologists, let alone outsiders, the meaning of "social structure" because these objects, so central to sociology, are almost always intangible. Lemert (2011: 79, emphasis removed) summarizes this "edifying enigma of sociology" well:

- "A sociology is nothing if it is not an account for social structures ...

- "Yet, the very structures for which a sociology exists are themselves, at the least, invisible (which is to say: they cannot be observed as such; they can only be reconstructed out of the data).

- "Hence, the essential obscurity of any sociology: It aims to be an empirical science of things (structures) that are not available to empirical observation".

Homans' (1975: 53) memorable pronouncement is just as true today as it was over four decades ago: sociologists use few words more often than social structure yet rarely ask what they mean by it, or, "social structure is usually treated as a taken-for-granted concept that is not in need of any explicit definition or discussion" (López and Scott 2000: 1).

The term "structure" in the social sciences has usually been used to describe three interrelated though distinct realms of reality: institutional structure, relational structure, and, more recently, embodied structure (López and Scott 2000; see also Scott 2011: ch. 6). Institutional structure refers to the normative or cultural patterns that characterize the "expectations that agents hold about each other's behavior and 
that organize their enduring relations with each other" (López and Scott 2000: 3), as expressed by Durkheim's notion of "collective representation," partially retained in Merton's structural analysis, and taken to new heights in Parsons' systems theory. Institutions are "subjective" in that they provide maps to guide behavior but are objective in that they shape behavior, are communicated, and are shared (e.g., Berger and Luckmann 1966). The paradox of the notion of institution-as-structure is that the distinction between structure and culture collapses (Martin 2009: 6, 17).

Relational structure refers to "patterns of causal interconnection and interdependence among agents and their actions, as well as the positions they occupy" (López and Scott 2000: 3). Relational structure as the "deeper" level of social structure (as opposed to normative expectations) is the foundation for various thinkers and schools of thought, including Marx, Spencer, Tönnies, Simmel, Radcliffe-Brown, Blau, social network theory, conflict theory, world-systems theory, and others. Blau's (1975: 3) definition of social structure captures the meaning of relational structure: the "patterns discernible in social life, the regularities observed, and configurations detected."

Drawing on Giddens (1979), Scott (2011: 171) defines embodied structures, the third form of structure in López and Scott's (2000) typology, as internalized structures, "the dispositions and tendencies of action". Embodied structure is parallel to Bourdieu's (1990) notion of habitus, discussed below. The present project can be thought of as an analysis of embodied structure, specifically an analysis of how institutional and relational structures are taken for granted in everyday experience, thereby remaining unnoticed despite shaping behavior and thought. This point is returned to below.

To summarize, social structures refer to temporally persistent and (usually) macro-level institutions and social relations. Although sociological thinking, which brings social structures to consciousness through aggregative, relational, and formal thinking, is rooted in the experiences of everyday life, the structural perspective sociologists strive to attain is not the typical perspective of everyday life (Gunderson 2021). For the typical person on the typical day, social structures are not the focus of attention and are, instead, relegated to the margin of experience.

\section{Structure Marginalization}

The previous section delineates what is meant by "social structure". This section conceptualizes "structure marginalization," the term used to describe the experiential processes through which social structures become taken for granted. I first explicate Gurwitsch's notion of "marginal consciousness" and then, drawing on Husserl's distinction between "activity" and "passivity," distinguish between active and passive processes of structure marginalization.

The "marginalization" in "structure marginalization" derives from Gurwitsch's (1964, 1985) notion of "marginal consciousness". Gurwitsch develops a three-tier model of conscious experience: 
[e]very field of consciousness comprises three domains or, so to speak, extends in three dimensions. First, the theme: that with which the subject is dealing, which at the given moment occupies the "focus" of his attention, engrosses his mind, and upon which his mental activity concentrates. Secondly, the thematic field, which we define as the totality of facts, co-present with the theme, which are experienced as having material relevancy or pertinence to the theme. In the third place, the margin comprises facts which are merely co-present with the theme, but have no material relevancy to it. (1964: 55f.; see Arvidson 1996)

The theme is one's focus of attention, the thematic field forms the context of the theme, as the "totality of items" that are "relevant" to the theme, and the margin is items that are simultaneously given or implied in experience yet have no relevance to the theme. For example, "one might be reading a book (theme), having associated thoughts about the book (thematic field), and a variety of marginal experiences irrelevant to the focal book reading: a sense of one's body, the room they are sitting in, and vague thoughts about dinner plans [margin]" (Yoshimi and Vinson 2015: 108). Gurwitsch (1966: 268) further breaks down the margin into two subdomains: the "halo" and "horizon". While he employs this distinction in different ways in his work, the distinction is important here in order to differentiate between irrelevant data that is co-present in experiences (the halo) while the horizon is the entire totality of different "orders of experience" implied in the halo (Gurwitsch 1964: 369; 1985: xlv, 34, 41).

Elsewhere I have made Gurwitsch's model more sociological by examining how social-structural conditions influence perception (Gunderson 2021, in review1). Important for this project is the argument that a "social horizon"-aspects of society that are taken-for-granted, tacitly known, ignored, or unknown-form the constant context of perception, influencing what we pay attention to (theme), what is considered relevant to what we attend to (thematic field), and what is considered irrelevant to what is attended to yet co-present in consciousness (halo). The social horizon is composed of social forces that are taken for granted or unknown in seemingly solitary experience despite forming the "background" and meaning-context of every perception. The purpose of this paper is to deepen the investigation of the experiential processes through which the social-structural world is typically taken for granted in the first place. I refer to the experiential processes that assign social forces to the margin (whether the halo or social horizon) as processes of "structure marginalization".

I categorize various processes of structure marginalization under two broad forms: passive structure marginalization and active structure marginalization. The descriptors "passive" and "active" are borrowed from Husserl, who developed and employed the concepts passivity and activity in distinct though interrelated ways throughout his work (see especially Husserl 1973, 2001; for commentaries Landgrebe 1981: ch. 2; Ryan 1977; Steinbeck 2001; Biceaga 2010; Junglos 2015). For example, there are passive and active levels of constitution, where passive constitution takes place in the "background" of experience "without the activity of the ego" (Landgrebe 1981: 53) through the pre-cognitive retention of perceptions and the "pre-predicative" tendency to identify similarities and differences of objects with 
past experiences (a "passive synthesis of likeness"), whereas active constitution proceeds through "acts of the Ego" (Husserl 1960: 77) such as judging and inferring, higher-level cognitive acts which presuppose passive constitution.

The goal here is not to plunge the depths of experience to locate the realm of a universal "original" or "pre-active" passivity that supposedly makes possible, or prefigures, higher-level active conscious acts. Instead, my goal is to examine the processes through which consciousness takes a pregiven social world for granted, specifically why social structures are typically given in the margin of experience rather than made thematic, despite the profound influence social structures have on experience. Husserl's passive/active distinction is employed to highlight two levels of this experiential process. Passive structure marginalization is the assignment of social structures to the margin without reflection, dialogue, evaluation, etc.- -without the creative and reflective participation of the ego. In contrast, active structure marginalization is the use of reflection, discourse, and other higher-level cognitive faculties to relegate items to marginal experience-structure marginalization "with the activity of the ego".

Both levels of structure marginalization are examined in more detail below with the aim of classifying concrete forms of passive and active forms of structure marginalization. To accomplish this goal, I draw on a wide range of thinkers, especially from the Marxist and phenomenological traditions. I ask that the reader forgives the lack of detail and, instead, judges the typology as a conceptual sketch.

\section{Passive Structure Marginalization: Material Reification, Ignorance, and Nullification}

To recap, passive structure marginalization is the assignment of social structures to the margin of experience without employing higher-level cognitive acts such as reflection and evaluation. The concept is meant to shine light on how social structures are "preconstituted" as irrelevant in everyday experience and why social-structural forces are typically taken for granted rather than given conscious, thematic awareness. Although I use the term "passive" in specific ways discussed below, it is important to note that the social world is always a sphere of "secondary" passivity passed down by the activity of our ancestors which is later taken for granted (see the concept of "social amnesia" below). This section identifies three interrelated processes of passive structure marginalization that account for this secondary passive marginalization of social structures: material reification, ignorance, and nullification. 


\section{Material Reification}

Material reification refers to the automatic process of assigning social structures to the margin of experience by adapting, via routine and habitual practices, to the effects of social-structural conditions. Material reification is the nearly mechanical adjustment and routinization of practices to "fit" already given and unquestioned conditions as well as the simultaneous implicit naturalization of these structures. Social structures are assigned to marginal consciousness for the seemingly simple reason that these conditions are already there-they happened to exist for enough time to be adapted to and thereby taken as natural and ignored as irrelevant. Material reification relegates structures to the margin of experience by passively adapting to their contours, demands, constraints, roles, rules, and expectations. The "reification" in material reification refers to the implicit naturalization of social structures and the "material" refers to the non-discursive and pre-reflective nature of this form of reification (see Gunderson 2021). ${ }^{1}$ This section summarizes the processes undergirding material reification, focusing on habit, and provides an illustration of material reification.

The complex and multilayered processes that establish material reification are hidden from common sense because they are so commonplace, yet, precisely because of their familiarity, remain undiscussed. However, these processes have been examined by sociologists and phenomenologists for a long time under the heading of many overlapping concepts, including habituation, routinization, institutionalization, and normalization (e.g., Berger and Luckmann 1966; Bourdieu 1990; Elias 1978; Ostrow 1979; Schutz and Luckmann 1973; May and Finch 2009). For example, much of Bourdieu's $(1977,1990)$ work draws attention to these pre-reflective processes that naturalize social life, especially his sociological development of Husserlian terms like doxa and habitus. Before Bourdieu, in his examination of the sphere of passive experience (see above), Husserl is also concerned with social life, culture, and intersubjectivity, especially in Ideas II (Husserl 1989; see Biceaga 2010: ch. 4). Through habit, one's participation in the social world becomes unreflective and taken for granted: "[t]aken-for-grantedness is one of the marks of habituation in general" (Biceaga 2010: 70). The development of habits passively marginalizes social structures because "all successfully required habitualities wind up concealing the original activity from which they sprang" (Biceaga 2010: 69). The term material reification is meant to signify the unthinking and "merely lived" naturalization of whatever social conditions happens to exist following habituation and similar processes, and the corresponding continual though unreflective assignment of socialstructural conditions to the margin of experience during habituation, routinization, institutionalization, and normalization.

To provide a simple example of material reification, I expand upon an illustration from Gurwitsch's (1979: 104ff.) early work Human encounters in the social world, where he develops a more sociological formulation of his field theory of

\footnotetext{
${ }^{1}$ It should be noted that other processes of passive structure marginalization also reify the given social order.
} 
consciousness. Gurwitsch asks us to imagine two men working together to cobble a street while a third stranger is observing the men work from the side. This partnership between the two workers is a social relation or style of being-together in which we interact with others to pursue a common goal. In this situation, from the perspective of one of the workers, the work-activity of cobbling is the theme and the fellow worker is a relevant part of the thematic field due to his functional role as a worker (Embree 1985: xxxix). In contrast, the stranger is relegated to the margin, co-present yet irrelevant to the theme. To expand upon this illustration with the concept of material reification, the following are unthinkingly taken for granted, as just the way things are: the reason they are cobbling a street in the first place, why they find themselves as wage workers, and the abstract typifications of "worker" and "stranger". These structural items are relegated to the margin for the exceedingly ordinary reason that they happen to exist and, through habituation, routinization, and similar processes, have long been naturalized. Further, depending on the era in which we imagine these cobblers and the stranger, it is possible that the social structures that form the background of this scene (e.g., a wage labor system) long preexisted those concrete humans who are filling preexisting roles.

In summary, material reification is the unthinking naturalization of the social system that happens to exist through the habitual and routine adaptation to its contours. We naturalize social structures and their effects because "they simply are there, and are accepted as inventory, as components of a known world" (Kosík 1976: 43). It is a form of passive structure marginalization because it pre-reflectively assigns socialstructural conditions to the margin of conscious experience, as irrelevant to what is thematic despite forming the context of experience.

\section{Ignorance}

Ignorance is a second prominent form of passive structure marginalization. By "ignorance" of social structures I mean a lack of conscious awareness of the historical formation, particularities, inner workings, geographical spread, and other details of social structures (see Gunderson, in review1). Ignorance passively assigns social structures to the margin of experience, specifically the social horizon, because a given social structure cannot be thematized or given in the thematic field if it is unknown. Just as deeper dimensions of reality are "implied" in the halo (see above), the history and complexity of social structures are implied, though obscured, in one's immediate and seemingly irrelevant surrounding social context. I focus on two interrelated forms of ignorance of social structure here: (1) social amnesia and (2) complexity reduction.

By "social amnesia" I mean the collective or individual forgetting of the historical particularity of the origins of a given social structure. Others have pointed out that society becomes an objective force because its historical formation is forgotten and then taken for granted (Berger and Luckmann 1966; Bourdieu 1990; Horkheimer and Adorno 1969). For example, Horkheimer and Adorno famously state that: "[a] 11 objectification [reification] is a forgetting" (1969: 230). Without the development of critical consciousness, all social formations are taken for granted by members 
of that society in part because its historical origins and distinctiveness are forgotten. Social structures, which were formed by concrete predecessors, take on a natural and universal form in the seemingly "immediate" consciousness of successors. Historically peculiar social relations and roles, such as nobility-peasant relations or cashier-customer relations, and social systems, such as the feudal stratification system or the internet, are passively relegated to the margin of experience, in part because, with time, their historical emergence and uniqueness are forgotten. Even when one is participating in these systems (e.g., searching COVID-19 symptoms on Google) and roles (e.g., checking out at a grocery store), the system itself (e.g., the internet) or role (e.g., customer) are passively assigned to the margin in part because these systems and relations have already hardened, ossified, or, to use a phenomenological phrase, "sedimented" into the unquestioned pseudo-natural reality of the social. To put this differently, these historically distinct relations, roles, and systems were thematized by many actors when these structures first emerged. For example, just the privatization of the commons was first thematized-problematized, resisted, discussed-and later taken for granted due to social amnesia, so too will many of our present concerns with emerging, new structures be taken for granted by our successors. Social amenia also impacts academic study. For example, Marx argues that historical forgetting is the cause of " $[\mathrm{t}] \mathrm{he}$ whole profundity of those modern economists who demonstrate the eternity and harmoniousness of the existing social relations" (1973: 85). The ignorance of social structures via social amnesia is one of the starting points of material reification (see above).

Along with social amnesia, a second dimension of ignorance of social structure is complexity reduction. The term "complexity reduction" is meant to signify that modern, complex social structures cannot be known in their entirety, not only due to the cognitive inability to fully grasp their historical emergence-hence the overlap with social amnesia-but also due to their present complexity. When one interacts with any given node of a social system, its multifaceted and often geographically expansive structural dynamics are hidden "within" or "behind" this node. These structures are relegated to the social horizon for the obvious reason that one cannot know what one does not know. However, there are different degrees of ignorance and knowledge of social structures. As ethnomethodologists emphasize (e.g., Garfinkel 1967: ch. 3), commonsense understanding of social structures is sufficient to carry out everyday tasks. However, there are always necessarily deeper levels of structure relegated to the margin. Small provides an apt example:

$[\mathrm{m}]$ ost people never see what they see. .... This is notoriously true of social relations. Only a few exceptional people have seen, for example, that a part of our own life is lived by people miles away, whose names we have never heard. Because certain men in Montana or the Argentine or Australia have raised a particular breed of sheep, we are able to wear some parts of the clothing at this moment on our bodies. Those distant people have been dressing us for years, while we have given scarce a thought to their existence. Who puts fork and spoon in our mouth at today's dinner? Not our hand alone. Some men have been raising wheat in Dakota, and potatoes in Michigan; others have been boiling salt in New York, others picking coffee in Java, and drying tea 
in Japan, and gathering spices in the isles of the sea; and porters have carried on their backs, and loaded on drays, and sails have strained, and boilers have steamed, and officials have inspected, and merchants have sworn, and traders have broken bulk, and factory hands have labored-all in the course of setting our table. (1897: 149f.)

To provide another example, the utter complexity of modern technological systems can obscure our relations with other humans and the environment (Hornborg 2001). This is also true of the technologists and engineers themselves, where no one specialist has total knowledge or control of any technical system (Simmel 1978: 456f.; Winner 1978).

To summarize, due to the forgotten history of the formation of social structures and their complexity, conscious experience can only thematize partial dimensions of a given social structure, thereby necessarily and passively assigning the rest of the structure to the margin.

\section{Nullification}

The nullification of social structure refers to the passive assignment of social structures to the margin of experience because further knowledge of the structure is not valued by the subject, a valuation which typically occurs automatically and unreflectively. Consciousness does not thematize social structures or take them as relevant to the given theme when they are not valued by an actor to achieve a given end. The "null" in "nullification," then, refers to "amounting to nothing" or "having no value" (Merriam-Webster Dictionary 2021). The point of the term is to draw attention to a process of passive structure marginalization in which social structures are rendered irrelevant by the subject because they are judged to be of no value to the subject. This section draws on Schutz and Kosík to conceptualize structure nullification and explain why it is typically a passive rather than active process.

As Schutz (1970) emphasizes in his theory of relevance, ${ }^{2}$ consciousness relegates deeper structural attributes to realms of irrelevance because these structures are either (1) not of pragmatic use to achieving everyday tasks and/or (2) perceived as out of one's control (Schutz 1964). We usually only typify aspects of social structures that are useful to our successful completion of tasks demanded by daily living (Schutz 1967a). For example,

[i]f I put my letter into a mailbox, I am perfectly familiar with the fact that there is a very good chance that after a certain lapse of time my message will reach the address. Of course, I know also the existence of post offices, and that the mail is carried by railroad, airplanes, or vessels from one place to another.

\footnotetext{
${ }^{2}$ I use the term "nullification" instead of, like Schutz, "irrelevance" because I think nullification is only one process by which social structures become irrelevant. In other words, arguing that items become irrelevant because they are of no use to the subject's goals, as Schutz argues, is only one experiential process through which items are assigned to marginal consciousness. One contribution of this paper is identifying a wider suite of processes of structure marginalization (see the conclusion).
} 
But I am not acquainted, nay I am even not eager to become acquainted, with how this whole organization works. (Schutz 1970: 147, emphasis added)

The reason the subject is "not eager to become acquainted" is doing so would be of no use to the subject. Kosík provides a similar example:

[p] eople use money and carry out the most complicated transactions with it without ever knowing, or having to know, what money is [emphasis added]. Immediate utilitarian praxis and corresponding routine thinking thus allow people to find their way about in the world, to feel familiar with things and manipulate them, but it does not provide them with a comprehension of things and of reality. (1976: 1f.)

The subject does not "have to know" what money is because knowledge of what money is, on a typical day for a typical person, is not relevant to the subject to achieve whatever the subject had planned to procure with money. For Marxists like Kosík (1976: 45), the need to engage in the utilitarian tasks of everyday life to survive in historically particular social structures, without attending to the human formation of these social structures, is the basis of reification, the formation of the "religion of the workaday".

Nullification as a process of passive structure marginalization refers to cases in which one does not actively think about whether it is worthwhile to gain more knowledge about an institution or web of social relations to attain one's ends. The nullification of social structure is categorized as a passive process as opposed to active process because the subject typically "immediately" or "automatically" judges, often on the grounds of usefulness/uselessness, that further knowledge of a given social structure is without value. For example, if one is reading a novel, one does not attend to the physical makeup of the book nor the factory, distribution, and sales commodity chains that brought the physical book into being because attending to its materiality and the system that produced it is of no use to accomplishing the task at hand. There is no need to actively reflect on the uselessness of thematizing these background structures - they are passively nullified. The question of its origins is not even asked. One does not engage in social-structural reflection because one's aims are already being realized without further knowledge of the given structure. Importantly, this is the case even though social structures provide the constant context of perception and often dictate what is worth attending to (e.g., Gunderson 2021). Further, the very grounds of valuation of what is considered relevant and irrelevant, that seemingly takes place spontaneously, is socially derived (Scheler 1980; Zerubavel 2015).

If material reification passively marginalizes social structures because they happen to exist, and ignorance passively marginalizes social structures because their history and totality are unknown or vaguely known, then nullification passively marginalizes social structures because attending to them is not valuable to the subject's project at hand. Social structures are given in marginal consciousness when thematizing them is unnecessary for achieving everyday tasks. One typically only seeks further knowledge about social structures if something goes wrong or something unexpected or unusual takes place (Schutz 1970). The following section examines 
the experiential processes that, following social disruptions or changes that forces subjects to thematize social structures, actively re-relegate social structures back to the margin.

\section{Active Structure Marginalization: Discursive Reification, Legitimation, and Helplessness}

Although social structures are typically assigned to the margin of experience through passive processes, their irrelevance can be ruptured through economic crises, wars, pandemics, and other harbingers of rapid social change: "[o]nly when things suddenly crack and break apart does it become obvious that there was a dynamic within them all the time; but ordinarily, things present an appearance of rest" (Nicolaus 1973: 30). Sudden "cracks" and "breaks" can bring taken-for-granted dimensions of social life into question, including their structural attributes. Social changes can bring formally ignored objects into attention (e.g., cigarette smoking went from a taken-for-granted activity to a "highly marked" activity), expand or contract moral attention (e.g., expansion of voting rights), and even change what is considered topically relevant to scientists (see Zerubavel 2015: 58f.). As Lucien Goldmann states:

all forms of consciousness express a provisional and mobile balance between the individual and his social environment; when this balance can be fairly easily established and is relatively stable, or when it can pass fairly easily from one form to another, men tend not to think about the problems raised by their relationship to the external world. On a social as well as on an individual plane, it is the sick organ which creates awareness, and it is in periods of social and political crisis that men are most aware of the enigma of their presence in the world. (1964: 48)

On the one hand, when society is "sick," or, "when millions of people are jolted out of this [regular and replicable] rhythm [of work, action, and life]" (Kosík 1976: 43), the awareness this sickness creates can be of the critical sort-the social origins of dialectical, two-dimensional thinking and social resistance. This is especially true when social crises and social-structural effects cause great harm. "With slight exaggeration," states Adorno (2000: 36) during a lecture, "society becomes directly perceptible when it hurts". Bourdieu describes how social changes which "[break] the immediate fit between the subjective structures and the objective structures" can lead to "the question[ing] of the natural or conventional character ... of social facts" (1977: 168f.). This questioning can cause conflict because those in power attempt to guard the taken-for-granted while the "dominated classes have an interest in pushing back the limits of doxa" (Bourdieu 1977: 169).

On the other hand, and far more often, social changes are, with time, once again taken for granted-as the "new normal". The purpose of this section is to describe the active experiential processes - those in which the ego is actively and consciously engaged - that re-marginalize social structures after they force themselves upon consciousness following social changes or when one is harmed by, or concerned about 
the harms caused by, social structures. I identify three processes of active structure marginalization: discursive reification, legitimation, and helplessness.

\section{Discursive Reification}

Discursive reification refers to the conscious, symbolic, explicit, and sometimes elaborate naturalization of society. In contrast to material reification, which pre-cognitively and implicitly naturalizes social life by taking what happens to exist as the way things are and adapting accordingly, discursive reification employs the creative awareness of the ego to achieve the same end (Gunderson 2021). Material reification is the unthinking, pre-reflective supposition that it is what it is, whereas discursive reification is the use of higher-order cognitive processes such as judgment and evaluation to explicitly give ascent to the idea that, in various renditions, "it is what it is, and it could not be different". Discursive reification actively marginalizes social structures to the margin by employing explanations for the status quo as implicit justifications for the status quo. This section identifies discursive reification's key lines of thinking with illustrations.

The content of discursive reifications may be simple or complex, but they all employ necessitarian, ahistorical (or transhistorical), universalistic, essentialist, and/ or naturalistic arguments to simultaneously explain and justify what historically formed social phenomena happen to exist. Discursive reifications are usually simple, uttered in an ad hoc way to explain away, or reduce cognitive dissonance surrounding, socially produced harms. For example, psychological research on the "meat paradox"- that most people think animals should not be harmed yet most people also eat animals (Loughnan et al. 2010)—shows that many omnivores overcome the meat paradox with one or more of the "Four Ns" of justification: meat eating is necessary (e.g., "Humans need meat to survive"), natural (e.g., "It is natural for humans to eat meat"), normal (e.g., "Society says it's okay"), and/or nice (e.g., "It tastes good") (Piazza et al. 2015: 116). Of the Four Ns, three are discursive reifications: it's necessary, it's natural, and it's normal (whereas it's nice is an aesthetic legitimation - see below). Indeed, necessitarian, naturalistic, and normalizing beliefs are the basic building blocks of discursive reifications.

One complex form of discursive reification is the literal naturalization of social reality through scientific argumentation (Zerubavel 2016; Gunderson 2020a: 24f.). For example, in a now infamous metaphor, popular psychologist Jordan Peterson (2018) compares the current social stratification system in human societies to the natural bases for the establishment of hierarchies between lobsters. Following a discussion of fight or flight mechanisms for conflict resolution among lobsters and how their serotonin and octopamine levels are affected by conflict, he makes the following leap:

[w] hen a defeated lobster regains its courage and dares to fight again it is more likely to lose again than you would predict, statistically, from a tally of its previous fights. Its victorious opponent, on the other hand, is more likely to win. It's winner-take-all in the lobster world, just as it is in human societies, where the top 1 percent have as much loot as the bottom 50 percent-and where the 
richest eighty-five people have as much money as the bottom three and a half billion. (Peterson 2018: 8)

There is nothing new about the appeal to, and desire for, a "natural" or "organic" social order, especially during periods of rapid social change, nor about this style of argumentation, from theories naturalizing wars as unavoidable due to natural selection to theories naturalizing human history as an outcome of biological laws (for discussion, see Paci 1972). Despite the diverse forms that discursive reifications take, they have a similar effect on interpretation and attention. All actively assign a theme (e.g., concern about high levels of inequality or concern about the suffering of animals) to the margin. Because the given social phenomenon is unchangeable, absolute, natural, necessary, etc., says discursive reification, it is irrelevant-not worth one's attention.

To return to the distinction between material and discursive reification, it is important to note that discursive reifications are built upon material reification. For example, one adjusts one's behaviors to the wage labor system, and naturalizes it, first and foremost because it happens to exist (material reification). However, the wage labor system is also discursively reified during primary and secondary socialization (e.g., "Do your best in school so you can get a good job"). Whenever the wage labor system - a marginalized social structure-is thrown into question, due to a prolonged economic crisis or high levels of inequality, for example, discursive reifications re-relegate this briefly thematized social structure back to the margin (e.g., "This is like a lobster battle over scarce resources-it can't be changed").

To summarize, discursive reification is the use of higher-order cognitive skills to marginalize social structures by marking them as fixed and inalterable. The following section examines the other side of the coin of active structure marginalization via justification: legitimation.

\section{Legitimation}

Legitimation refers to the use of moral, aesthetic, or theological concepts, beliefs, and lines of argument to justify the social order. "Legitimation justifies the institutional order by giving a normative dignity to its practical imperatives," as Berger and Luckmann (1966: 93) put it. For our purposes, discursive reifications are justifications for social phenomena through renditions of "This is the way things are" while legitimations are justifications for social phenomena through renditions of "This is the way things are, and this is right, or at least not so bad". 3 After describing the

\footnotetext{
3 Although the section on legitimation draws from Berger and Luckmann's (1966: 61) account of legitimation, it is worth noting that they would likely conceptualize what I term "discursive reification" above as a form of "legitimation" because discursive reifications are also "ways by which it [the institutional world] can be 'explained' and justified". I use legitimation in a more restricted sense, to refer to an appeal to normative criteria to justify the status quo, whereas discursive reification appeals to "the facts" to justify the status quo. Discursive reification and legitimation overlap to the extent that they both justify a socially contingent reality. In this sense, both discursive reification and legitimation can both be understood as forms of essentialism that make a socially created order seem absolute (Zerubavel 2016). Further, both discursive reification and legitimation de-problematize social phenomena, thereby allowing the given phenomenon to move to the margin of experience.
} 
origins of legitimation in social amnesia and how legitimation pushes potentially problematic social structures to the margin of experience, this section then explains why "capitalist realism" (Fisher 2008), the current era's foremost legitimation, is adaptable enough to survive the current "legitimation crisis".

There are different levels of legitimation, ranging from the linguistic objectifications of "incipient legitimation" (e.g., kinship words such as "cousin" or "father" implicitly justify the given kinship system) to "bodies of theoretical tradition that integrate different provinces of meaning and encompass the intuitional order in a symbolic totality," or, "symbolic universes" (Berger and Luckmann 1966: 94, 95). However, long before symbolic universes are formed to lend normative support to entire social orders, legitimation is first rooted in passive processes. Like discursive reification, the origins of legitimation, an active form of structure marginalization, have deeper roots in passive processes of structure marginalization. Berger and Luckmann (1966) identify the genesis of legitimation in the forgetting of history, described as "social amnesia" above, clashing with the requirements of social reproduction. More specifically, because a socially created reality "comes to the new generation as a tradition rather than a biographical memory," the "original meaning of the institutions is inaccessible to them in terms of memory. It, therefore, becomes necessary to interpret this meaning to them in various legitimating formulas" (Berger and Luckmann 1966: 61f.).

Legitimations are especially important to maintain aspects of social life that may strike new members of a society, from children to immigrants, as unusual, absurd, or worthy of attention and questioning. The elementary features of legitimation-not to mention discursive reification ("Because those are the rules," "That's just the way things are," etc.) (see Berger and Luckmann 1966: 94)—are present in nearly all conversations between parents and children when the latter asks questions about events they interpret as unjust or harmful in some way. For example, a child may ask her parents why a man standing in the cold is asking for money. Depending on the age of the child and the legitimations that the parents happened to have internalized during socialization, the reply will likely range from "The man is down on his luck and needs a little help" to "The man made poor life decisions and is taking advantage of suckers". Importantly here, it is exceedingly rare for the legitimations employed in such situations to bring the social-structural forces that cause poverty, homelessness, and related issues into question. In other words, legitimations use moral evaluation and judgement, higher-order cognitive skills, to actively push the topical effects of social structures from the theme to the margin. "As long as there is still one beggar around, there will be myth," says Walter Benjmain (1999: 400).

The power of legitimation to relegate social structures to the margin is not limited to the consciousness of children. For example, Piketty (2020) asks how such massive levels of wealth inequality can persist, reminding us that all elites must employ ideological justifications for their disproportionate hold on resources and power. Yet how is ideological legitimation possible in an era that is so clearly marked by what Habermas (1973: 47) calls a "legitimation deficit," when "it is not possible by administrative means to maintain or establish effective normative structures to the extent required"? How is it possible, for example, to legitimate, with normative 
criteria, the fact that the richest 657 Americans increased their wealth by $\$ 1.3$ trillion during a pandemic in which 78 million Americans lost their jobs (Institute for Policy Studies 2021)? Today, normative legitimation typically takes place indirectly, through the assertion that the current social formation of capitalism is not as bad as the alternatives (Fisher 2008). In a world in which there is no existing alternative to capitalism, there is no "alternative symbolic order" (Berger and Luckmann 1966) that poses a threat to the stability of capitalism. The best we can hope for, says the indirect legitimation of capitalism, is a slightly less brutal form of capitalism, "global capitalism with a human face" (Žižek 2000: 63). The interplay of legitimation with discursive reification is clear in capitalist-realist legitimation, which relegates social-structural effects like massive levels of inequality back to the margin, to once again be taken for granted, through the consolation that, "This may be bad, but there is no alternative".

In summary, legitimations push social structures to the margin of experience through reflective judgement and evaluation. When the effects of social structures thrust themselves upon consciousness as themes, legitimation of the given system acts as a process of active structure marginalization.

\section{Helplessness}

If discursive reification actively marginalizes social structures through renditions of "It is what it is," and legitimation actively marginalizes social structures through renditions of "It is right, or not so bad, anyway," then helplessness actively marginalizes social structures through renditions of fatalistic shrugs and "What can you do?" Even if one is aware of social structures, or concerned about their harmful effects, these phenomena can be actively re-marginalized when the subject affirms the experience of their uncontrollability. This section identifies helplessness's foundation in the passive process of structure nullification, argues that widespread cynicism is an adaptation to helplessness, and provides an illustration of how helplessness actively marginalizes social structures.

Helplessness is experientially rooted in the passive process of marginalizing features of the social world that are immediately taken as non-valuable for achieving everyday practical aims, or, "structure nullification" (see above). One reason that social structures are nullified in experience is the implicit, immediate knowledge of a lack of control over background social conditions and the focusing of attention on one's surroundings that can be manipulated to achieve practical aims (Schutz 1964). Helplessness is the reflective awareness that one does, in fact, lack power to significantly alter structural conditions even if one is concerned about their harmful effects. Lukács (1971) traces the origins of helplessness to our inability to control the expansive chains of commodity production that seem to operate by their own laws. In such conditions, we adopt a "contemplative" or powerless (Lopez 2019) stance toward the social world, which appears as a reified, unchangeable totality because it really does operate outside our solitary control. Although I focus on an active awareness of helplessness here, helplessness is rooted in specific politicaleconomic conditions that render one helpless (Gunderson, in review2). 
Widespread cynicism is an adaptation to helplessness (Gunderson, in review2). Disappointed by the letdowns of the utopian dreams of old, and disillusioned by ideology critique, the modern cynic is aware enough to know that "this is all a sham" but, for the sake of self-preservation, continues to perform everyday practices that reproduce the social order (see Sloterdijk 1987; Žižek 1989). "With some things we feel dismay but with most things we can't really give a damn," says Sloterdijk (1987: 99). Helplessness in the form of cynicism marginalizes social structures by permitting one to "know" the truth about social structures (e.g., that money is a materialization of social conditions and there is "nothing magical about it") yet still push the implications of this knowledge to the margin, to continue to operate the same in practice as if we did not really know (e.g., we behave as if money really does embody wealth) (Žižek 1989: 31).

The way in which helplessness marginalizes social structures is helpfully illustrated by returning to the example of the problem of massive levels of inequality. In a review of Piketty's book Capital and Ideology (2020), mentioned above, Jäger and Leusder (2020: 42) make the following point about how inequality carries on unchallenged: "[ $\mathrm{t}$ ]he stability [of modern capitalism] probably owes far more to a mood of resignation, as people make peace with a world that is hostile to their flourishing. They know this world to be a product of human agency, but they cannot control it". In other words, the conscious experience of helplessness is a more potent process of structure marginalization than legitimation. Social structures can continue unchallenged free from legitimation so long as isolated actors are powerless to control the forces that shape their lives.

Along with discursive reification and legitimation, helplessness is a third pillar of active structure marginalization. All three processes employ higher-order acts of consciousness to experientially marginalize social structures, even after they are made problematic by the harmful effects of social structures or rapid social change. Further, each active process of structure marginalization is preceded by, and built upon, passive processes of structure marginalization.

\section{Conclusion}

This paper identifies experiential processes through which social structures become taken for granted, termed processes of "structure marginalization". Passive processes of structure marginalization relegate social structures to the margin of experience without the use of higher-order cognitive acts such as evaluation and reflection. Examples include adapting to social structures via routine and habitual practices (material reification), a lack of conscious awareness of the complexity, historical formation, and other details of social structures (ignorance), and rendering social structures irrelevant when they are unreflectively and immediately judged to be of no value for achieving ends (nullification). Active processes of structure marginalization reflectively and discursively relegate social structures to marginal consciousness. Examples include the use of naturalistic and necessitarian explanations for the social order that implicitly justify it as inalterable or "just the way things are" (discursive reification), normative justifications for the status quo (legitimation), 
and conscious awareness of one's powerlessness to control social-structural conditions (helplessness). Active processes of structure marginalization originate in passive processes. The goal of the typology is to explain why social structures typically remain unproblematic and unnoticed in everyday life experience, even during periods of social crisis and change or when existing structures produce harmful effects.

The typology makes contributions to social phenomenology and the theory of social reproduction. The central contribution to social phenomenology is categorizing and describing multiple processes through which social structures are relegated to marginal consciousness. I hope that the variety of processes identified will be useful for future research. In comparison to Schutz, who emphasizes impracticality and lack of control as the basis for the irrelevancy of social-structural forces in mundane experience (see especially Schutz 1964), termed the "nullification" of social structures above, the comparative strength of the typology developed here is the analytical range it offers. Further, the broad distinction between passive and active forms of marginalization may have more general use for phenomenologists. Social structures are only one type of "object" that can be relegated to marginal consciousness. The distinction may prove useful for theorizing why other items of experience are typically given in the margin of experience or actively marginalized.

The theory of structure marginalization makes three contributions to the theory of social reproduction. First, it seeks to show why, at an experiential level, the current social order lumbers on despite the obviousness of its contradictions. One goal of this paper is to identify how, even during periods of crisis and change, social structures are re-assigned to marginal consciousness rather than extensively reflected on. The implicit counterfactual is periods of history-usually eras of crisis-in which formerly taken-for-granted social structures are made problematic in everyday life and resisted in collective groups. Second, distinguishing between both passive and active processes of structure marginalization sidesteps the common charge of functionalism leveled at theories of social reproduction (see Himmelweit 1991: 470). Although this point is not examined closely in this paper, the analysis of active structure marginalization above indicates that social contradictions and crises allow for moments of collective reflection and purposeful social change. In other words, structure marginalization, though ubiquitous, is not predetermined. Third, the concept of passive structure marginalization provides more analytical depth to the conceptualization of ideology as merely-lived, unreflective practical adaptations to preexisting institutions (Althusser 1971) before it is a coherent set of ideas and beliefs.

Further analysis should examine the relation between processes of structure marginalization and the formation of social structures. This paper examines how social-structural forces are taken for granted in experience and, thereby, reproduced in everyday life. It does not examine how the process of structure marginalization itself contributes to the production and "reality" of these social-structural forces. Although questions about the ontology and genesis of social structure are distinct from the question of the phenomenology of the experience of social structure, it is important to remind readers that-aside from the material outcomes of social structures (e.g., highways, the hardware of information systems, military technology), the concrete, bodily practices of humans, and the energy flows that power both-social structures themselves are immaterial and "exist" only insofar as they are taken for 
granted by the vast majority of a social group. The implications of this fact are not explored here.

\section{References}

Adorno, T. W. (1982). Against epistemology: a metacritique: studies in Husserl and the phenomenological antimonies. MIT Press.

Adorno, T. W. (2000). Introduction to sociology. Stanford University Press.

Althusser, L. (1971). Ideology and ideological state apparatuses. Lenin and philosophy and other essays (pp. 127-186). Monthly Review Press.

Arvidson, P. S. (1996). Toward a phenomenology of attention. Human Studies, 19(1), 71-84.

Benjamin, W. (1999). The arcades project. Harvard University Press.

Berger, P. L., \& Luckmann, T. (1966). The social construction of reality: a treatise in the sociology of knowledge. Anchor Books.

Biceaga, V. (2010). The concept of passivity in Husserl's phenomenology. Springer.

Blau, P. M. (Ed.). (1975). Approaches to the study of social structure. Free Press.

Bourdieu, P. (1977). Outline of a theory of practice. Cambridge University Press.

Bourdieu, P. (1990). The logic of practice. Stanford University Press.

Brekhus, W. (1998). A sociology of the unmarked: redirecting our focus. Sociological Theory, 16(1), $34-51$.

Chua, B. H. (1977). Delineating a Marxist interest in ethnomethodology. The American Sociologist, 12(1), 24-32.

Embree, L. (1985). Gurwitsch's phenomenology of the margin, body, and being. In L. Embree (Ed.), Marginal consciousness (pp. xi-xlv). Ohio University Press.

Elias, N. (1978). The civilising process. Blackwell.

Foucault, M. (1985). The use of pleasure: the history of sexuality (Vol. 2). Vintage Books.

Fisher, M. (2008). Capitalist realism: is there no alternative? Zero Books.

Garfinkel, H. (1967). Studies in ethnomethodology. Prentice-Hall.

Giddens, A. (1979). Central problems in social theory: action, structure, and contradiction in social analysis. University of California Press.

Goffman, E. (1974). Frame analysis. Harper and Row.

Goldmann, L. (1964). The hidden god: a study of tragic vision in the Pensées of Pascal and the tragedies of Racine. Routledge and Kegan Paul.

Gunderson, R. (2020a). Making the familiar strange: sociology contra reification. Routledge.

Gunderson, R. (2020b). The mundane dialectic of enlightenment: typification as everyday identity thinking. Human Studies, 43(4), 521-543.

Gunderson, R. (2021). Must cognitive sociology heed capitalism? Attention and marginal consciousness in political-economic context. Journal for the Theory of Social Behaviour. https://doi.org/10.1111/ jtsb. 12269 .

Gunderson, R., Stuart, D., \& Houser, M. (2020). A political-economic theory of relevance: explaining climate change inaction. Journal for the Theory of Social Behaviour, 50(1), 42-63.

Gunderson, R. (in review1). Human-computer interaction research needs a theory of social structure: the dark side of digital technology systems hidden in user experience.

Gunderson, R. (in review2). Powerless, stupefied, and repressed actors cannot challenge climate change: real helplessness as a barrier between climate concern and action.

Gurwitsch, A. (1964). The field of consciousness. Duquesne University Press.

Gurwitsch, A. (1966). Studies in phenomenology and psychology. Northwestern University Press.

Gurwitsch, A. (1979). Human encounters in the social world. Duquesne University Press.

Gurwitsch, A. (1985). Marginal consciousness. Ohio University Press.

Habermas, J. (1973). Legitimation crisis. Beacon Press.

Himmelweit, S. (1991). Reproduction. In T. Bottomore (Ed.), A dictionary of Marxist thought (pp. 469471). Blackwell.

Horkheimer, M., \& Adorno, T. (1969). Dialectic of enlightenment. Continuum. 
Homans, G. C. (1975). What do we mean by social "structure"? In P. M. Blau (Ed.), Approaches to the study of social structure. New York: Free Press.

Hornborg, A. (2001). Symbolic technologies: machines and the Marxian notion of fetishism. Anthropological Theory, 1(4), 473-496.

Husserl, E. (1960). Cartesian meditations: an introduction to phenomenology. Martinus Nijhoff.

Husserl, E. (1973). Experience and judgment. Northwestern University Press.

Husserl, E. (1989). Ideas pertaining to a pure phenomenology and to a phenomenological philosophy: second book studies in the phenomenology of constitution. Kluwer.

Husserl, E. (2001). Analyses concerning passive and active synthesis: lectures on transcendental logic. Kluwer.

Institute for Policy Studies. (2021). A year into crisis, billionaires could pay for 2/3 of Biden's COVID relief bill with their pandemic profits. Common Dreams. https://www.commondreams.org/newsw ire/2021/03/11/year-crisis-billionaires-could-pay-23-bidens-covid-relief-bill-their-pandemic

Jäger, A., \& Leusder, D. (2020). The prophet of inequality. Jacobin, 38, 39-42.

Junglos, M. (2015). The constitution of judgments in Husserl's phenomenology. Discusiones Filosóficas, 16(27), 31-47.

Kosík, K. (1976). Dialectics of the concrete. D. Reidel.

Landgrebe, L. (1981). The phenomenology of Edmund Husserl: six essays. Cornell University Press.

Lemert, C. C. (2011). The structural lie: small clues to global things. Paradigm Publishers.

Lopez, D. (2019). The conversion of Georg Lukács. Jacobin. https://jacobinmag.com/2019/01/lukacshungary-marx-philosophy-consciousness.

López, J., \& Scott, J. (2000). Social structure. Open University Press.

Loughnan, S., Haslam, N., \& Bastian, B. (2010). The role of meat consumption in the denial of moral status and mind to meat animals. Appetite, 55(1), 156-159.

Lukács, G. (1971). History and class consciousness: studies in Marxist dialectics. MIT Press.

Martin, J. L. (2009). Social structures. Princeton University Press.

May, C., \& Finch, T. (2009). Implementing, embedding, and integrating practices: an outline of normalization process theory. Sociology, 43(3), 535-554.

Marx, K. (1973). Grundrisse. Vintage.

Merriam-Webster Dictionary. 2021. "Null.” https://www.merriam-webster.com/dictionary/null.

Nicolaus, M. (1973). Foreword. In K. Marx (Ed.). Grundrisse. Vintage.

Ostrow, J. M. (1979). Culture as a fundamental dimension of experience: a discussion of Pierre Bourdieu's theory of human habitus. Human Studies, 4(1), 279-297.

Paci, E. (1972). The function of the sciences and the meaning of man. Northwestern University Press.

Peterson, J. (2018). 12 rules for life: an antidote to chaos. Penguin Random House.

Piazza, J., Ruby, M. B., Loughnan, S., Luong, M., Kulik, J., Watkins, H. M., \& Seigerman, M. (2015). Rationalizing meat consumption. The 4Ns. Appetite, 91, 114-128.

Piketty, T. (2020). Capital and ideology. Harvard University Press.

Ryan, W. F. (1977). Passive and active elements in Husserl's notion of intentionality. The Modern Schoolman, 55(1), 37-55.

Sallach, D. (1973). Class consciousness and the everyday world in the work of Marx and Schutz. Insurgent Sociologist, 3(4), 27-37.

Scheler, M. (1980). Problems of a sociology of knowledge. Routledge and Kegan Paul.

Schutz, A. (1964). The well-informed citizen: an essay on the social distribution of knowledge. In A. Brodersen (Ed.), Collected papers, vol 2: studies in social theory (pp. 120-134). Martinus Nijhoff.

Schutz, A. (1967a). On multiple realities. In M. Natanson (Ed.), Collected papers I: the problem of social reality (pp. 207-259). Martinus Nijhoff.

Schutz, A. (1967b). The phenomenology of the social world. Northwestern University Press.

Schutz, A. (1970). Reflections on the problem of relevance. Yale University Press.

Schutz, A., \& Luckmann, T. (1973). The structures of the life-world. Northwestern University Press.

Scott, J. (2011). Conceptualising the social world: principles of sociological analysis. Cambridge University Press.

Simmel, G. (1978). The philosophy of money. Routledge and Kegan Paul.

Sloterdijk, P. (1987). Critique of cynical reason. University of Minnesota Press.

Small, A. W. (1897). The sociologists' point of view. American Journal of Sociology, 3(2), 145-170.

Steinbeck, A. J. (2001). Translator's introduction. In A. J. Steinbeck (Ed.), Analyses concerning passive and active synthesis: lectures on transcendental logic. Boston: Kluwer. 
Stuart, D., Gunderson, R., \& Petersen, B. (2020). Climate change solutions: beyond the capital-climate contradiction. University of Michigan Press.

Winner, L. (1978). Autonomous technology: technics-out-of-control as a theme in political thought. MIT Press.

Wright, E. O. (2010). Envisioning real utopias. Verso.

Yoshimi, J., \& Vinson, D. W. (2015). Extending Gurwitsch's field theory of consciousness. Consciousness and Cognition, 34, 104-123.

Zerubavel, E. (1997). Social mindscapes: an invitation to cognitive sociology. Harvard University Press.

Zerubavel, E. (2015). Hidden in plain sight: the social structure of irrelevance. Oxford University Press.

Zerubavel, E. (2016). The five pillars of essentialism: reification and the social construction of an objective reality. Cultural Sociology, 10(1), 69-76.

Zerubavel, E. (2018). Taken for granted: the remarkable power of the unremarkable. Princeton University Press.

Žižek, S. (1989). The sublime object of ideology. Verso.

Žižek, S. (2000). The fragile absolute, or, why is the Christian legacy worth fighting for? Verso.

Publisher's Note Springer Nature remains neutral with regard to jurisdictional claims in published maps and institutional affiliations. 